\title{
The Importance of TDA Thermal Analysis in an Automated Metallurgical Process
}

\author{
Łukasz Petrus ${ }^{a}$, Andrzej Bulanowski ${ }^{a}$, Jakub Kołakowskia, Jakub Sobieraja, Tomasz Paruch ${ }^{a}$,

 \\ a PGO, Odlewnia Żeliwa Śrem Sp. z o.o., 1 Staszica St., 63-100 Śrem \\ b AGH University of Science and Technology in Kraków, Faculty of Foundry Engineering, 23 Reymonta St., 30-059 Kraków \\ c Silesian University of Technology, Department of Foundry Engineering, 7 Towarowa St., 44-100 Gliwice \\ *e-mail: krzysztof.janerka@polsl.pl
}

(C) 2021 Authors. This is an open access publication, which can be used, distributed and reproduced in any medium according to the Creative Commons CC-BY 4.0 License requiring that the original work has been properly cited.

Received: 30 September 2021/Accepted: 8 November 2021/ Published online: 25 November 2021

This article is published with open access at AGH University of Science and Technology Press

Paper presented at the III International Conference of Casting and Materials Engineering ICCME 2021: Casting of Lightweight Components in Automotive, Aviation and Space Technologies. November 4-5, 2021, Krakow, Poland.

\begin{abstract}
The article presents the results of research and work related to the implementation of the research and development project POIR.01.01.01-00-0120/17 co-financed by the EU, through the NCBR, entitled: Innovative technology using thermal analysis, TDA, of self-feeding manufacturing of high-quality cast iron to produce new generation, enhanced performance casts. In many foundries, thermal derivative analysis (TDA) is used in addition to chemical analysis to evaluate the physical and chemical properties of an alloy while it is still in the melting furnace or ladle and before it is poured into the mold. This fact makes it possible to improve the metallurgical quality of the alloy by introducing alloying additives, carburizers or modifiers into the furnace as part of the pre-modification or primary or secondary modification in the ladle or when pouring into molds. Foundry machinery (modifier dosing systems and spheroidizing station) is very important in these operations. Only the full synergy of modern equipment with modern technology ensures high quality and repeatability of the casting process. The article mainly discusses the obtained parameters of TDA analysis (with the use of the ITACA system) at different stages of melting and how to improve them by using modern and fully automated dosing systems (Itaca OptiDose, ItacaWire and ItacaStream). Special attention was paid to the minimum temperature of the eutectoid. The change of its value after the modification process, its influence on the quality of the melted metal, a very strong correlation with the number of nuclei and the number of graphite precipitations in the casts were shown.
\end{abstract}

\section{Keywords:}

ductile iron, grey cast iron, thermal derivative analysis, melting automation, modification

\section{INTRODUCTION}

Production of high-quality castings with complex shapes without defects requires modern equipment used directly in the manufacturing process (melting furnaces, spheroidization and modification stations, molding stations) and quality assessment systems at its various stages, including chemical analysis, thermal derivative analysis (TDA), mechanical properties, metallographic tests and non-destructive tests (RT, UT).

Thermal derivative analysis, which records the cooling curve and crystallization curve determined from it, is best suited for metallurgical quality assessment [1]. This analysis allows the evaluation of the physicochemical state of the metal and captures important parameters not shown by chemical analysis. An example is a modification process that results in a significant change in the properties of cast iron without any discernible change in the chemical composition. Among the most important parameters recorded and calculated are the characteristic melt temperatures of Tliquidus, Temin, Temax, Tsolidus, VPS index, Rec recalescence value. The most common systems used in foundries are ITACA [2] (used in this project), ATAS [3, 4] and QUIK-LAB [5]. The theoretical basis of thermal derivative analysis is discussed in many literature references $[1,6-10]$.

\section{PROGRESSION AND METHODOLOGY OF THE RESEARCH}

The research was carried out in production conditions in Odlewnia Żeliwa Śrem Sp. z o.o. (Iron Foundry in Śrem) as a part of testing a modern, automated production line using metallurgical quality control based on thermal derivative analysis TDA on individual stages (melting, secondary treatment and mould pouring). 
There is no doubt that the repeatable process of producing good quality cast iron begins with the selection of feedstock materials. It is important to ensure that they are of good quality, properly stored and accurately weighed. The melting process was carried out in medium frequency crucible furnaces with a crucible capacity of $8 \mathrm{t}$. The furnaces are equipped with charging trucks with a vibration system. Charged mixtures are weighed based on the batch compositions transferred to the fully automated control system of the crane and the alloy additive hoppers (Figs. 1 and 2).

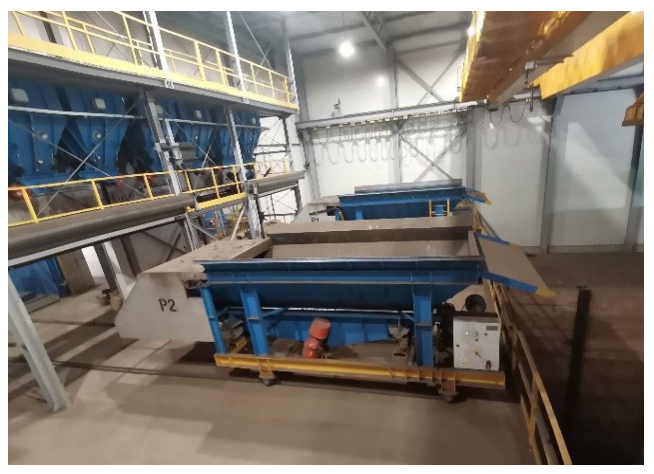

Fig. 1. Automated charge material weighing and dosing system

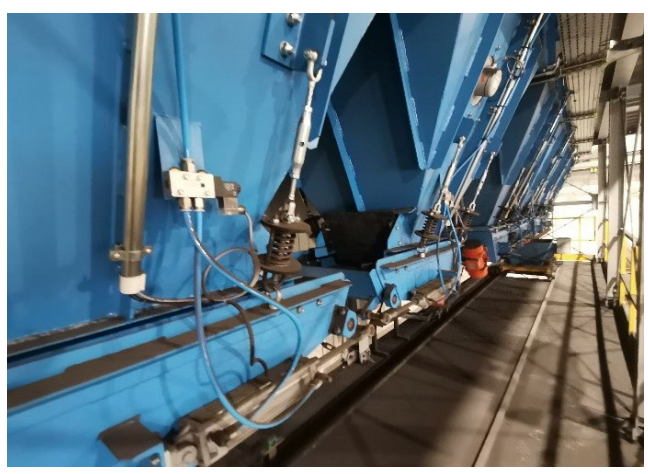

Fig. 2. Alloy additive dosing units

After the charge is melted, a sample is taken for chemical analysis and TDA samplers are filled. Based on the results obtained, alloying and modifying additives (premodification) are introduced if necessary. The analysis results are automatically entered into the system, which has the ability to store "learning" data and make corrections.

The metal is then poured into a ladle. During this process, modifiers are introduced into the metal stream using an automated system (ItacaOptiDose) and their weight is calculated and depends on the previous thermal analysis (Fig. 3).

The system allows introduction of one of the five modifiers found in the hoppers. The modifier is weighed into a feeder and introduced into the stream of overflowing metal (from furnace to ladle).

The next step in the production of ductile iron is the spheroidization process. This process is carried out on stations enabling the introduction of spheroidizing master alloy in the form of PE flexible wire (ItacaWire - Fig. 4). The amount of PE fed is calculated automatically by the system based on the previous chemical analysis, temperature and thermal derivative analysis (VPS). Wire feeding rate mainly depends on the size of the ladle and the weight of the metal to be processed. Before the process, the temperature is measured by immersing the thermocouple in the treatment ladle, and the measurement result is automatically transferred to the system. The modifier (secondary modification) is also introduced in this station.

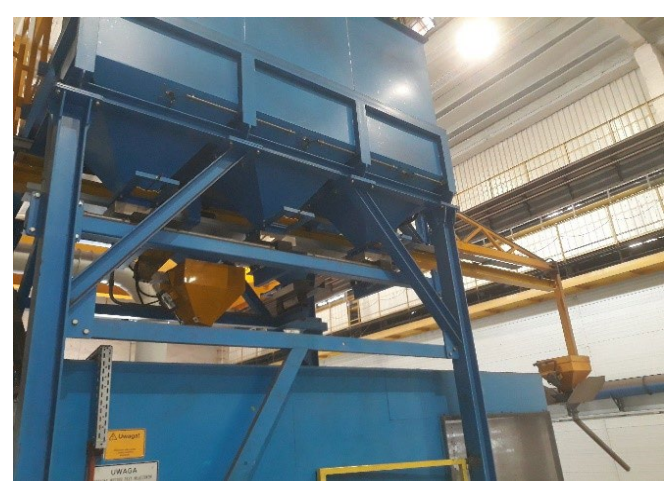

Fig. 3. Automated system for introducing modifiers on the metal stream when pouring into a ladle

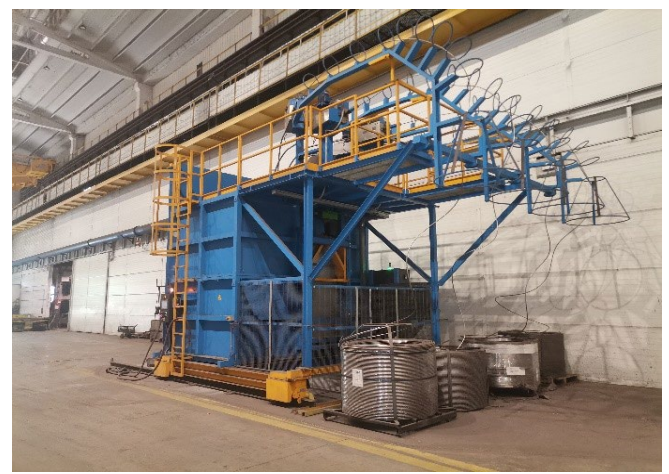

Fig. 4. The station for spheroidization and modification with the PE method

A great influence on metallurgical quality is exerted by secondary modification, which is considered to be the most effective modification step. It is well known that the effects of both the magnesium treatment process and the addition of modifiers are reduced over time. By moving the modification further to the late stage of pouring, this problem is minimized. Often a small modifier addition at the final stage can replace a much larger addition introduced in earlier stages [11]. On automatic casting lines, the modifier is most often introduced into the metal stream when pouring into the molds. When filling large molds, an automated system (Itaca XLStream) is used to allow precise dosing of the modifier (Fig. 5). This dispenser is a combination of screw and injector dosing units.

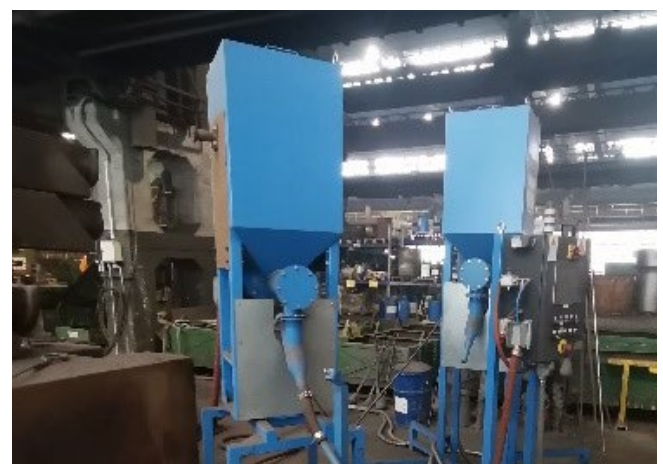

Fig. 5. Itaca XL Stream dosing system 
As mentioned earlier, to evaluate the course of the modification process and at the same time the metallurgical quality, it is best to use the thermal-derivative analysis $[5,6]$. This results from the fact, among other factors, that the modifier addition is small and it affects the change in chemical composition to a very small extent (mostly imperceptible), but it is clearly visible in the course of the cooling curve as shown in Fig. 6. The dashed line represents unmodified cast iron and the solid line is modified cast iron. The modification reduces the degree of subcooling required for graphite precipitation (red arrow). In addition, it extends graphite formation and growth by increasing solidification time (blue arrow) [12].

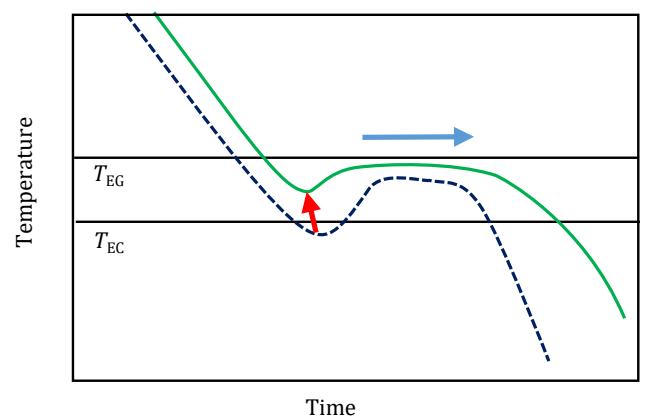

Fig. 6. Effect of modification on the cooling curve [12]

One of the most important parameters of this analysis is the minimum temperature reached during eutectic solidification (Temin). At this point, the latent heat of crystallization is equal to the heat given up during cooling. Temin is the most important indicator of cast iron nucleation. The higher this temperature, the better the nucleation potential. Below $1135^{\circ} \mathrm{C}$ nucleation is considered low and there is a high risk of primary carbides occurrence in the casting. Between $1135^{\circ} \mathrm{C}$ and $1145^{\circ} \mathrm{C}$ nucleation is considered optimal and the risk of primary carbides will depend on casting wall thickness. Above $1145^{\circ} \mathrm{C}$ nucleation is very good and there is no risk of primary carbides. The changes in TeMin temperature and nucleation index obtained by primary and secondary modification using different modifiers are shown below. These are silicon-based modifiers with $\mathrm{Ba}, \mathrm{Sr}, \mathrm{Zr}$, metallurgical silicon carbide ( $\mathrm{SiC}$ ) and graphite carburizer (C). Modifiers with $\mathrm{Bi}$ and Ce were also tested in the secondary modification process.

Exemplary TDA curves for cast iron obtained before primary modification (Ba2p melt) and after primary modification (Ba2k melt) are shown in Figures 7 and 8.

Temin temperature changes before ( $p$-indexes - red bars) and after primary modification (k-indexes - green bars), for different modifiers are shown in Figure 9.

A very important parameter about which information can be obtained from the derivative curve is the nucleation rate of the liquid metal. It depends on, among other things, the process temperature of the alloy, cast iron melting and holding times, as well as the carbon and silicon content. For the initial cast iron to produce ductile iron, the value of this parameter should be 100. At lower values, the nucleation index can be increased by introducing a modifier, $\mathrm{FeSi}, \mathrm{SiC}$ or $\mathrm{C}$. This correction can be done in the furnace (premodification) and in the ladle (primary modification). The nucleation rate values obtained during the study are shown in Figure 10.

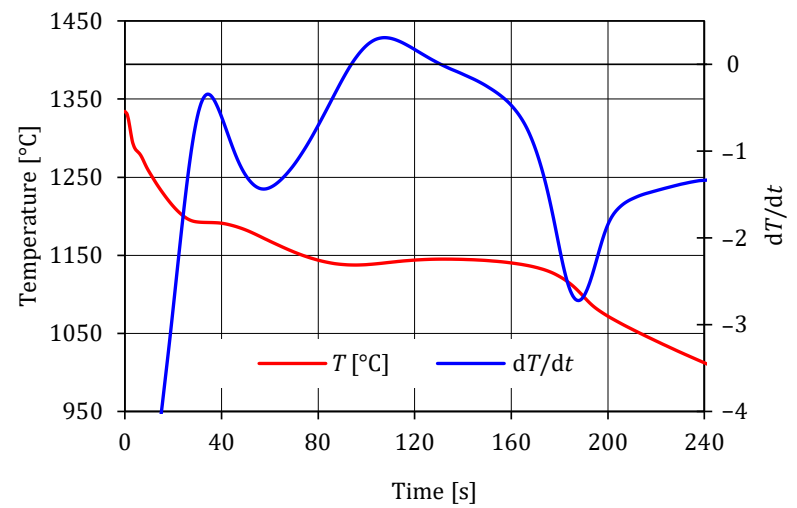

Fig. 7. The cooling and crystallization curve for the Ba2p melt - before primary modification

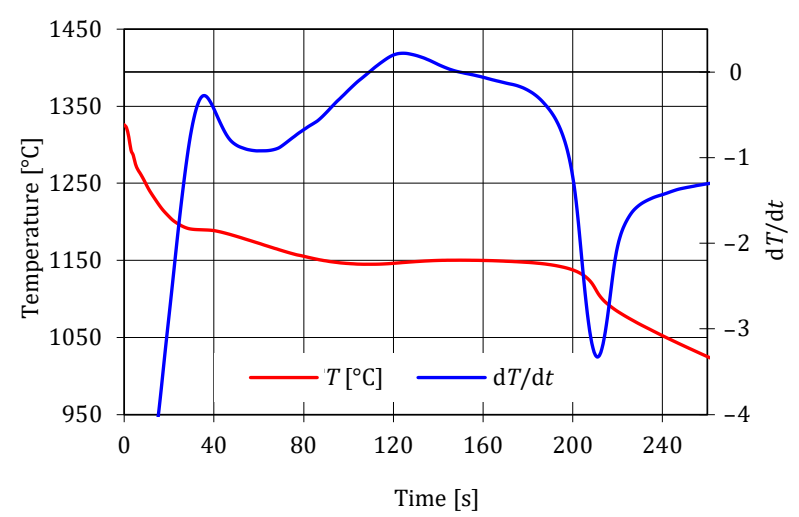

Fig. 8. The cooling and crystallization curve for the Ba2k melt - after primary modification

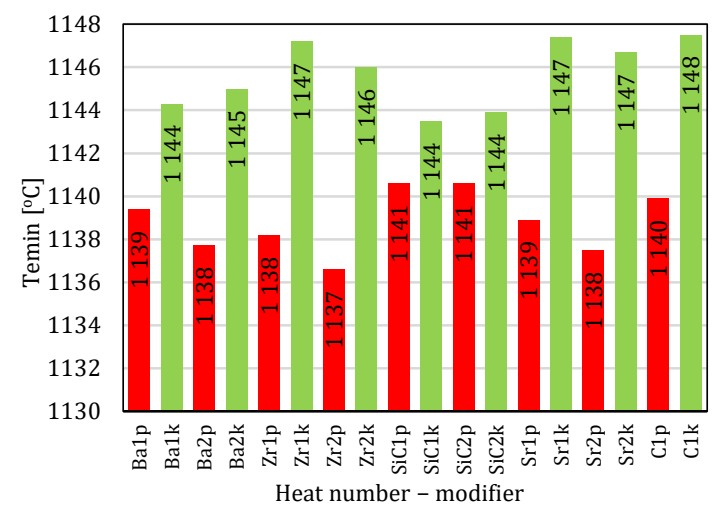

Fig. 9. Temin temperature change after primary modification



Fig. 10. Change in number of nuclei after primary modification 
One of the parameters of thermal and derivative analysis is VPS, which is the value of the angle formed by the cooling rate, whose value is related to the formation of shrink holes. In the initial cast iron for ductile iron production and in gray iron, this value should be in the range of 16-23. For ductile iron, this value should be $35-55$. If the indices are higher than the limit values then the tendency to form shrink holes. If the ratios are lower then there is a risk of graphite degeneration. The effect of the modification process on the VPS value is shown in Figure 11.

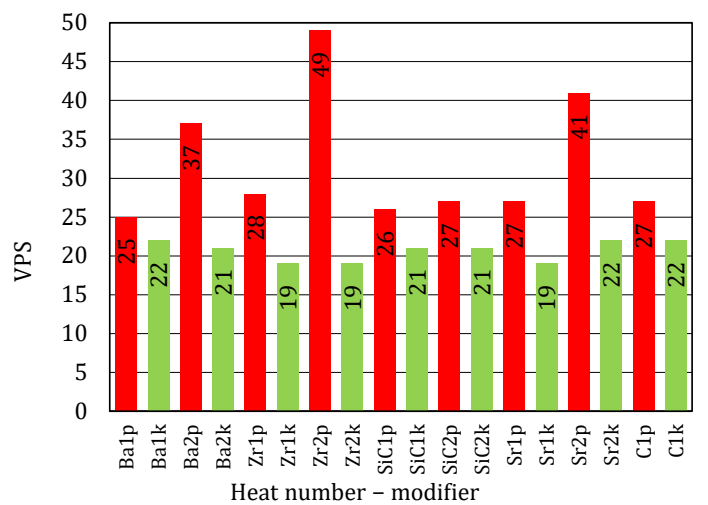

Fig. 11. VPS ratio change after primary modification

From the results obtained, it can be concluded that Thermal Derivative Analysis shows clear changes in the parameters characterizing the smelted cast iron after the primary modification process. This relates to the increase in Temin temperature and nucleation rate, and a decrease in VPS. The assumed values of these parameters were obtained regardless of the modifier used.

An analysis of the dependence of the number of nuclei indicated by the TDA curve recording process on the Temin temperature was performed during the melt execution. The results are shown in Figure 12.

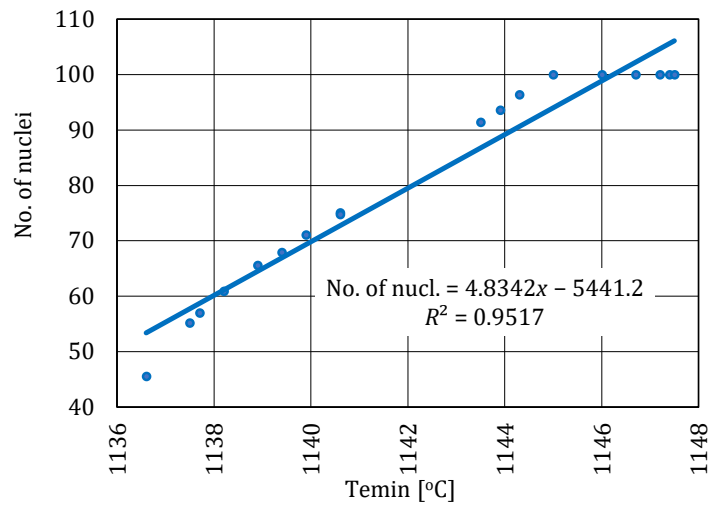

Fig. 12. Number of nuclei as a function of Temin temperature (values obtained from solidification and crystallization curves)

Within the research, the process of the secondary modification of ductile iron was also carried out. Some of the results obtained determining the effect of different modifiers on Temin temperature are shown in Figure 13. In all melts, the number of nuclei (TDA analysis) was 100.

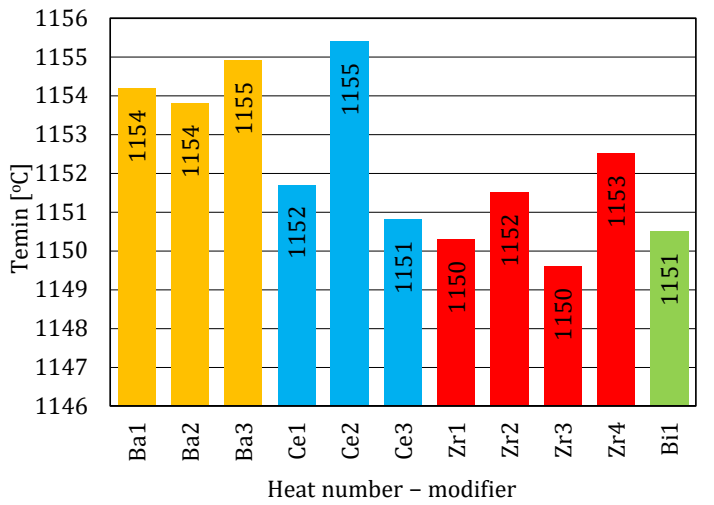

Fig. 13. Temin temperature after secondary modification

Metallographic studies of the microstructure were performed for all the melts presented above. The obtained results of measurements of graphite precipitations for individual modifiers are shown in Figure 14.

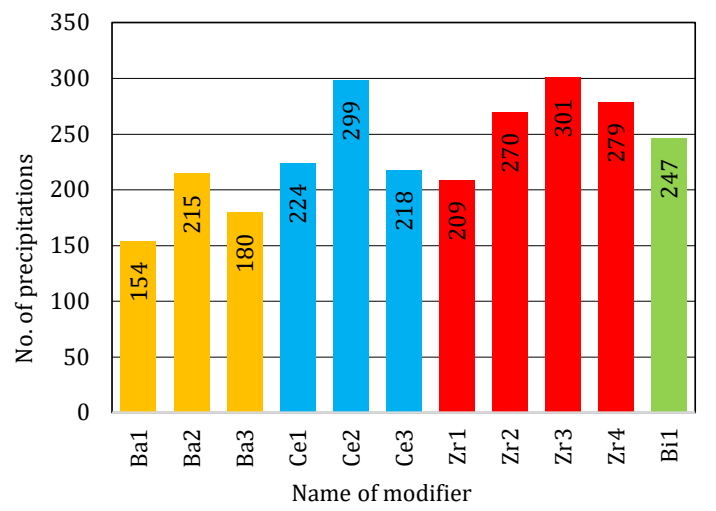

Fig. 14. Number of graphite precipitations after secondary modification

In order to verify the thermal analysis parameters, the obtained Temin temperature recording results were related to the measured number of graphite precipitations found in metallographic studies. In Figure 15, a chart and the relationship between these parameters are shown.

The obtained results confirm the high correlation between Temin (TDA curves) and the number of graphite precipitations (metallographic studies).

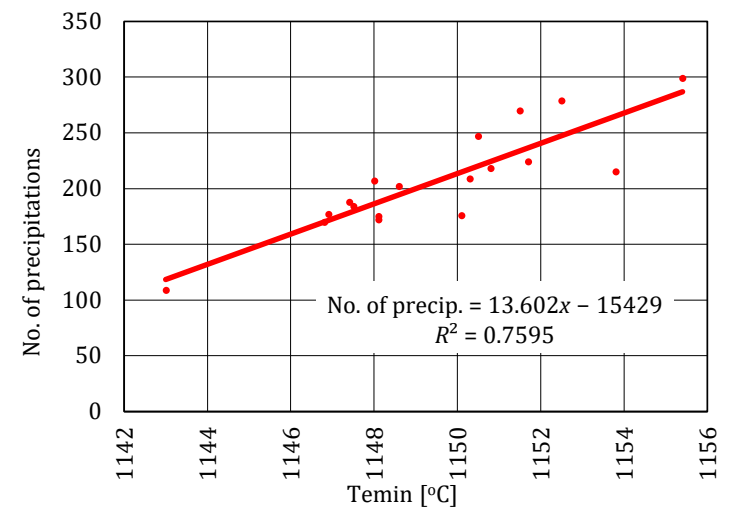

Fig. 15. Measured number of graphite precipitations in ductile iron as a function of temperature Temin 


\section{SUMMARY}

The studies carried out to evaluate the effectiveness of the modification process by thermal derivative analysis allow the capture of even small additives introduced into the liquid metal. This was demonstrated on only three parameters analyzed (Temin, nucleation index, and VPS index). The obtained values of these parameters confirmed the assumed expectations regarding their increasing or decreasing trends. This research also demonstrated the ability to fully control the melting process from the charge weighing stage to the stage of pouring into the molds. Control based on thermal derivative analysis TDA provides collection of a very large amount of data enabling consequently "learning" of the system and the possibility to correct and control metallurgical quality at the earliest possible stage of melting and secondary (post-furnace) processing. In total, there are approx. 45 different temperatures and parameters for each filled sampler.

In order for such a control system to function properly, it is necessary, first of all, to have automated equipment to perform individual tasks. This is confirmed by the applied solutions, including modern melting furnaces, dosing of charge materials, as well as modifiers and spheroidizers.

Only the synergy of these two components (control system and working system) ensures the possibility of a fully repeatable, high-quality, controlled metallurgical process.

\section{Acknowledgments}

The studies were conducted as part of the project implemented by Odlewnia Żeliwa Śrem Sp. z o.o. co-financed by the European Union from the Regional Development Fund as part of the Smart Growth Operational Program 2014-2020, project number: POIR. 01.01.01-00-0120/17, Project entitled: Innovative technology using thermal analysis, DTA, of self-feeding manufacturing of high-quality cast iron to produce new generation, enhanced performance casts.

\section{REFERENCES}

[1] Petrus Ł., Bulanowski A., Kołakowski J., Brzeżański M., Urbanowicz M., Sobieraj J., Matuszkiewicz G., Szwalbe L. \& Janerka K. (2020). The influence of selected melting parameters on the physical and chemical properties of cast iron. Archives of Foundry Engineering, 20(1), 105-110.

[2] ITACAX ${ }^{\mathrm{TM}}$ (2021). Final iron control. Retrieved from http://www. proservicetech.it/itacax-thermal-analysis-final-iron-quality-control/ [accessed 1.09.2021].

[3] ATAS MetStar (2021). Productbrochure. Retrieved from:https:// www.novacast.se/product/atas/ [accessed 1.09.2021].

[4] Persson P.-E., Ignaszak Z., Fransson H., Kropotkin V., Andersson R. \& Kump A. (2019). Increasing Precision and Yield in Casting Production by Simulation of theSolidification Process Based on Realistic MaterialData Evaluated from Thermal Analysis (Using the ATAS MetStar System).Archives of Foundry Engineering,20(1),109-116.

[5] Heraeus (2021). Thermal Analysis. Retrieved from https://www. heraeus.com/en/hen/products_and_solutions_hen/foundry/ thermal_analysis/thermal_analysis.html [accessed 1.09.2021].

[6] Gawroński J., Szajnar J. Jura Z. \& Studnicki A. (2004). Profesor Stanisław Jura - twórca teorii i zastosowań przemysłowych diagnostyki oraz zużycia metali i stopów [Professor Stanislaw Jura - the creator of theory and the industrial used of diagnostics and the wear of metals and alloys] Archiwum Odlewnictwa, 4(16), 1-74.

[7] Stefanescu D.M. (2015). Thermal Analysis - Theory and Applications in Metalcasting. International Journal of Metalcasting, 9(1), 7-22. Doi: https://doi.org/10.1007/BF03355598.

[8] Chisamera M., Riposan J., Stan S., Stefan E. \& Costache G. (2015). Thermal analysis control of in-mould and ladle inoculated grey cast irons. China Foundry, (6)2, 145-151.

[9] Pietrowski S. \& Gumienny G. (2002). Metodyka przygotowania oceny jakości żeliwa sferoidalnego z zastosowaniem metody TDA [Methodology for the preparation of ductile iron quality assessment using the ATD method]. Archiwum Odlewnictwa, 2(6), 249-256.

[10] Stawarz M. \& Szajnar J. (2003). Ocena jakości żeliwa sferoidalnego metodą ATD [Assessment of ductile iron quality by TDA]. Archiwum Odlewnictwa, 3(10), 199-206.

[11] Borse S.C. (2014). Review on Grey Cast Iron Inoculation. International Journal of Innovative Research in Science, Engineering and Technology, 3(4), 30-36.

[12] Hartung C. \& Logan R. (2021). What is an inoculant and what does it do? Retrieved from: https://www.abifa.org.br/wp-content/uploads/2019/10/19.09.2019-09H45-WHAT-IS-AN-INOCULANT-AND-WHAT-DOES-IT-DO.pdf [accessed 15.09.2021]. 